\title{
Mycobacterium doricum sp. nov.
}

\author{
1 Regional Mycobacteria \\ Reference Centre, \\ Microbiology and Virology \\ Laboratory, Careggi \\ Hospital, 50134 Florence, \\ Italy \\ 2 Department of Clinical \\ Microbiology, Umberto \\ I-Torrette Hospital, 60120 \\ Ancona, Italy \\ 3 Deutsche Sammlung von \\ Mikroorganismen und \\ Zellkulturen, 38124 \\ Braunschweig, Germany \\ 4 Department of Zoology \\ and Animal Biology, \\ University of Geneva, \\ 1224 Chêne-Bougeries, \\ Switzerland \\ 5 Institute of Medical \\ Microbiology and Hygiene, \\ University of Regensburg, \\ 93053 Regensburg, \\ Germany \\ 6 Institute of Infectious \\ Diseases and Public Health, \\ University of Ancona, \\ 60100 Ancona, Italy \\ 7 SmartGene, 8032 Zurich, \\ Switzerland
}

\author{
Enrico Tortoli, ${ }^{1}$ Claudio Piersimoni, ${ }^{2}$ Reiner M. Kroppenstedt, ${ }^{3}$ \\ Juan I. Montoya-Burgos, ${ }^{4}$ Udo Reischl, ${ }^{5}$ Andrea Giacometti ${ }^{6}$ \\ and Stefan Emler
}

\begin{abstract}
Author for correspondence: Enrico Tortoli. Tel: + 39055 4279199. Fax: + 390554279830. e-mail: e.tortoli@libero.it
\end{abstract}

\begin{abstract}
A novel mycobacterial species is described in this study. The strain was isolated from the cerebrospinal fluid of a severely immunocompromised AIDS patient. It was scotochromogenic and slow-growing. Characteristic features for its differentiation from other mycobacteria are its lipid pattern and the unique gene sequences within the hypervariable regions of the 165 rDNA. The strain shows susceptibility to current antimycobacterial drugs. The pathogenicity of the novel mycobacterium and its clinical significance are not certain, as the neurological symptoms of the patient could also be due to concomitant infection with Cryptococcus neoformans. The name Mycobacterium doricum sp. nov. is proposed for the novel mycobacterium; the type strain is strain FI$13295^{\top}$ ( = DSM 44339 ${ }^{\top}=$ CIP $106867^{\top}$ ).
\end{abstract}

Keywords: Mycobacterium doricum sp. nov., taxonomy, identification, phylogeny

\section{INTRODUCTION}

In recent years, the introduction of new technologies has perhaps impacted the mycobacteria more than any other bacterial genus. Comparative 16S rRNA gene sequencing (Kirschner et al., 1993) and HPLC of cellwall mycolic acids (Butler et al., 1992) have allowed better characterization of phenotypically indistinguishable organisms, leading to the detection of several novel species (Cage \& Saubolle, 1997) whose epidemiological and clinical relevance remains undetermined (Böttger, 1994; Kiehn \& White, 1994).

In this context, a slowly growing, acid-fast organism was isolated from the spinal fluid of an AIDS patient. The strain could not be identified conclusively by biochemical tests and it showed an unknown profile by HPLC analysis, suggestive of a novel species within the genus Mycobacterium. Therefore, a multi-disciplinary study employing different identification techniques was undertaken in order to clarify the taxonomic position of the novel mycobacterium. Our data in-

The GenBank accession number for the 16S rDNA sequence of strain FI$13295^{\top}$ is AF264700. dicate that this isolate represents a novel species, for which the name Mycobacterium doricum sp. nov. is proposed.

\section{METHODS}

Case report and strain isolation. In November 1990, a 50year-old homosexual man with AIDS $\left(28 \mathrm{CD} 4^{+}\right.$lymphocytes $\mu \mathrm{l}^{-1}, 3500$ white blood cells $\mu \mathrm{l}^{-1}$ and seropositive for HIV p24 antigen) was admitted to hospital with fever, chills, severe weight loss, cough, headache and a stiff neck. He had been monitored since 1988 for HIV infection and treated repeatedly for Pneumocystis carinii pneumonia. The patient had not reported any history of tuberculosis and he had not been treated for any mycobacterial infection during the follow-up. Cerebrospinal fluid was taken and analysed, with the following results: 5 white blood cells $\mu^{-1} ; 0.88 \mathrm{~g}$ protein $1^{-1}$ (normal range: $\left.0 \cdot 20-0 \cdot 50\right) ; 2 \cdot 0 \mathrm{mmol}$ glucose $1^{-1}$ (in comparison with $6.0 \mathrm{mmol} \mathrm{l}^{-1}$ present in the blood); stains for acid-fast bacilli, Gram stain and India ink mount were negative; cultures for bacteria and fungi remained sterile. A cryptococcal antigen assay, performed on spinal fluid and serum, was strongly positive and blood cultures yielded Cryptococcus neoformans. The patient was treated with amphotericin B and 5-fluorocytosine but, unfortunately, despite treatment, he died 6 weeks after hospitalization. Necropsy was not done. Shortly thereafter, spinal fluid culture inoculated onto Lowenstein-Jensen medium yielded 
Table 1. Comparison of the mycolic acid patterns of strain $\mathrm{Fl}-13295^{\top}$ and other slowly growing mycobacteria

Taxa are identified as: 1, strain FI-13295 $; 2$, Mycobacterium bohemicum; 3, Mycobacterium conspicuum; 4, Mycobacterium cookii; 5, Mycobacterium gordonae; 6, Mycobacterium interjectum; 7, Mycobacterium lentiflavum; 8, Mycobacterium scrofulaceum; 9, Mycobacterium szulgai; 10, Mycobacterium xenopi. All taxa contain $\alpha$-mycolates.

\begin{tabular}{|lllllllllllll}
\hline Mycolic acid type & $\mathbf{1}$ & $\mathbf{2}$ & $\mathbf{3}$ & $\mathbf{4}$ & $\mathbf{5}$ & $\mathbf{6}$ & $\mathbf{7}$ & $\mathbf{8}$ & $\mathbf{9}$ & $\mathbf{1 0}$ \\
\hline$\alpha^{\prime}$-Mycolates & - & - & - & + & - & - & & + & & - & - & - \\
Methoxymycolates & + & - & - & - & + & - & - & - & + \\
Ketomycolates & - & + & + & - & + & + & & + & + & + \\
Wax esters & + & + & + & + & - & + & - & + & - \\
\hline
\end{tabular}

approximately 50 colonies of a slow-growing, pigmented mycobacterium (strain FI-13295 $)$.

Conventional identification methods. Cultural features, i.e. growth rate, colony morphology, the nature of the pigment, produced in the dark or after photoinduction, and the ability to grow at temperatures ranging from 25 to $45^{\circ} \mathrm{C}$, were investigated on Lowenstein-Jensen medium. Inhibition tests included tolerance to thiophene-2-carboxylic acid hydrazide $\left(1 \mu \mathrm{g} \mathrm{ml} \mathrm{m}^{-1}\right)$, thiacetazone $\left(10 \mu \mathrm{g} \mathrm{ml} \mathrm{m}^{-1}\right)$, p-nitrobenzoate $\left(500 \mu \mathrm{g} \mathrm{ml}^{-1}\right)$, hydroxylamine $\left(500 \mu \mathrm{g} \mathrm{ml}^{-1}\right)$, oleate $\left(250 \mu \mathrm{g} \mathrm{ml}^{-1}\right)$, isoniazid $\left(1 \mu \mathrm{g} \mathrm{ml}^{-1}\right)$ and sodium chloride $(5 \%)$ and growth on MacConkey agar without crystal violet (Kent \& Kubica, 1985).

The following biochemical features were investigated: niacin accumulation, nitrate reductase, 3-d arylsulfatase, semiquantitative catalase, heat-stable catalase $\left(\mathrm{pH} 7,68^{\circ} \mathrm{C}\right)$, tellurite reductase, Tween 80 hydrolysis, $\beta$-glucosidase and urease (Kent \& Kubica, 1985).

Acid-alcohol-fastness was determined by Ziehl-Neelsen and auramine $\mathrm{O}$ staining.

Drug susceptibility. The susceptibility pattern of the strain was studied by using the radiometric system according to the macrodilution method adopted for the Mycobacterium avium complex (Siddiqi et al., 1993). The similarity of the growth kinetics of the novel strain in liquid medium to those of $M$. avium made possible the adoption of such a technique, the requirements of which were all fulfilled. Minimal inhibitory concentrations of 12 drugs were determined.

Lipid analyses. Mycolic acids were investigated by TLC on whole-organism methanolysates, as described previously (Minnikin et al., 1984). The HPLC profile of mycolic acid bromophenacyl esters was obtained with a $\mathrm{C}_{18}$ Ultrasphere XL cartridge column (Beckman) on a System Gold model (Beckman) instrument according to the standard procedure (Butler et al., 1992; CDC, 1996; Tortoli \& Bartoloni, 1996).

Forty milligrams of saponified wet biomass, methylated and extracted as described previously (Miller, 1982), was used for analysis of fatty acid methyl esters, alcohols and mycolic acid cleavage products. They were subsequently separated by GLC using a model 5898A gas chromatograph (Hewlett Packard). The Microbial Identification System software (Microbial ID) was used to identify the fatty acids.

Analysis of 16S rDNA. Extraction of DNA was carried out as described previously (Kirschner et al., 1993). After mech- anical lysis of a single heat-inactivated colony, amplification of the entire 16S rRNA gene (16S rDNA) was carried out as described previously (Kirschner et al., 1993). The entire 16S rDNA sequence was established by overlapping direct sequencing of both strands of the amplicons using fluorescently labelled dideoxy dye terminators on an automated DNA sequencer (ABI 373A; Perkin-Elmer Biosystems). Proof-reading of the sequences of both strands was performed with the Sequence Navigator software (Perkin-Elmer Biosystems), while comparison with other mycobacterial sequences was carried out within the SmartGene IDNS database system. Finally, searches in GenBank were carried out by using the BLAST algorithm proposed on the GenBank web-site (http://www.ncbi.nlm.nih.gov/blast/).

Determination of the DNA $\mathbf{G}+\mathbf{C}$ content. After hydrolysis and dephosphorylation of isolated DNA, nucleosides were separated by reverse-phase HPLC (Tamaoka \& Komagata, 1984). A Nucleosil 100-5 $\mathrm{C}_{18}$ column was used and nonmethylated lambda phage DNA, with a $\mathrm{G}+\mathrm{C}$ content of $49.858 \mathrm{~mol} \%$ (Sanger et al., 1982), was used as the calibrator reference.

Phylogenetic analysis. The sequence of strain FI-13295 ${ }^{\mathrm{T}}$ was aligned with $16 \mathrm{~S}$ rDNA reference sequences from closely related mycobacterial species using the Genetic Data Environment software version 2.2 (Larsen et al., 1993). Although alignment gaps were not removed, regions with uncertain alignment within the reference sequences imported from GenBank were omitted, as well as parts at both ends of the gene. The neighbour-joining method was used for construction of a phylogenetic tree (Saitou \& Nei, 1987) after distances were corrected for multiple hits and for unequal transition-to-transversion rates according to Kimura's two-parameter model (Kimura, 1980). The 16S rDNA sequence of Nocardia asteroides was used as an outgroup. Tree branches were reproduced by performing parsimony analysis and bootstrapping.

\section{RESULTS}

\section{Morphological and cultural properties}

Cells of strain FI-13295 $5^{\mathrm{T}}$ were acid-alcohol-fast, nonmotile, did not form spores and were rod-shaped. Growth was observed on Lowenstein-Jensen medium after 2 weeks of incubation at temperatures ranging from 25 to $37^{\circ} \mathrm{C}$. Colonies were smooth and scotochromogenic. Growth was inhibited by presence of thiacetazone, p-nitrobenzoate, hydroxylamine, 


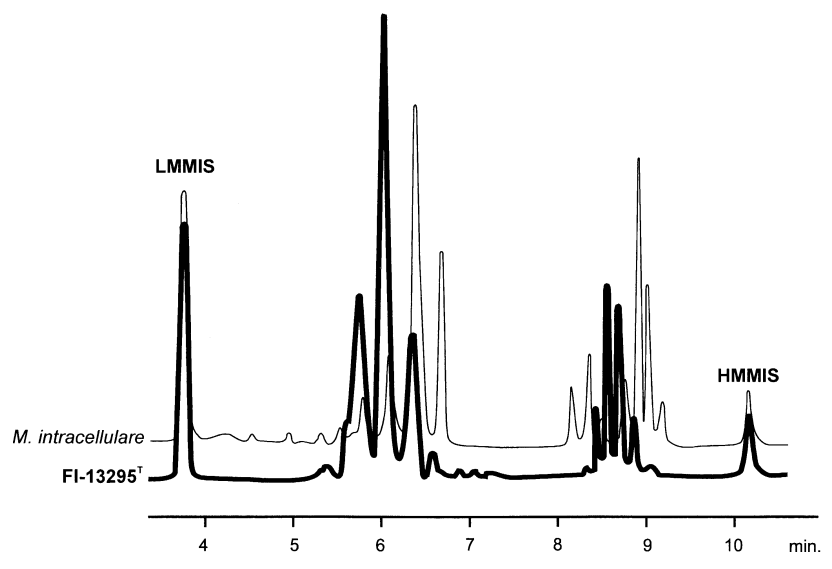

Fig. 1. HPLC mycolic acid profile of strain $\mathrm{FI}-13295^{\top}$ compared with that of Mycobacterium intracellulare. LMMIS, Lowmolecular-mass internal standard; HMMIS, high-molecular-mass internal standard.

isoniazid, oleate or sodium chloride in the culture medium; growth was not obtained on MacConkey agar. The presence of thiophene-2-carboxylic acid hydrazide had no inhibitory effect on growth.

\section{Biochemical properties}

The strain possessed nitrate reductase, urease and tellurite reductase activities. Accumulation of niacin, $\beta$-glucosidase, Tween hydrolysis and arylsulfatase gave negative results. Catalase, which was clearly below $45 \mathrm{~mm}$ of foam, was inhibited at $68^{\circ} \mathrm{C}$.

\section{Antimicrobial susceptibility}

Strain FI-13295 $5^{\mathrm{T}}$ was susceptible in vitro to all antimicrobial drugs tested. Minimal inhibitory concentrations were (in $\mu \mathrm{g} \mathrm{ml} \mathrm{m}^{-1}$ ): amikacin, 0.12 ; azithromycin, 0.5 ; clarithromycin, $0 \cdot 12$; ciprofloxacin, $0 \cdot 12$; clofazimine, $0 \cdot 06$; ethambutol, $0 \cdot 25$; isoniazid, $0 \cdot 12$; ofloxacin, $0 \cdot 25$; rifabutin, $0 \cdot 06$; rifampicin, $0 \cdot 12$; sparfloxacin, $0 \cdot 12$; and streptomycin, $0 \cdot 25$.

\section{Lipid analysis}

TLC of the mycolic acid methyl esters of strain FI$13295^{\mathrm{T}}$ revealed $\alpha$-mycolates and wax esters. Also, small amounts of methoxymycolates were found. This combination of mycolic acids is an uncommon pattern among the best-known scotochromogenic, slowly growing mycobacteria (Table 1).

Strain FI-13295 $5^{\mathrm{T}}$ showed the typical fatty acid pattern found in most mycobacteria, but its similarity to any mycobacterial pattern stored in the MIDI fatty acid database was very low because of obvious differences in amounts of single fatty acids. The fatty acid pattern of strain FI-13295 ${ }^{\mathrm{T}}$ was composed of straight-chain saturated and unsaturated fatty acids, with 16:0 (27\%) and $18: 1$ cis $9(26 \%)$ and $16: 1$ cis $9(9 \%)$ being the best represented. The 10-methyl-branched tuberculostearic acid $(16 \%)$ and the alcohols octadecanol (19\%) and eicosanol (1\%) were also found. This was expected, as these alcohols are the cleavage products of the esters and co-elute with the fatty acid methyl esters during the $\mathrm{GC}$ analysis.

The HPLC pattern of mycolic acids was characterized by two clusters of peaks (Fig. 1) that did not overlap with any previously reported mycobacterial profile.

\section{$\mathbf{G}+\mathbf{C}$ content}

The $\mathrm{G}+\mathrm{C}$ content of the DNA of strain FI-13295 was $66.5 \mathrm{~mol} \%$.

\section{$16 S$ rDNA sequence analysis}

Sequence analysis of PCR-amplified DNA from strain FI-13295 ${ }^{\mathrm{T}}$ yielded a unique $16 \mathrm{~S}$ rDNA sequence of $1450 \mathrm{bp}$ and the sequence was characteristic of a mycobacterial species. In contrast to the slow growth of the strain in culture, the sequence was characteristic of a rapidly growing mycobacterium. It was characterized by the deletion of a stretch of 12 nucleotides between positions 413 and 425 within helix 18 (alignment with Mycobacterium tuberculosis reference sequence MTU16SRN from GenBank). A GenBank search showed close $(>99 \%)$ similarity to sequence AF 107039, derived from an as-yet unpublished isolate, 'Mycobacterium monacense', which also has uncertain pathogenicity to humans (U. Reischl, unpublished results).

\section{Phylogenetic analysis}

A phylogenetic tree (Fig. 2) revealed a position of strain FI-13295 ${ }^{\mathrm{T}}$ close to Mycobacterium phlei, Mycobacterium flavescens, Mycobacterium smegmatis and Mycobacterium thermoresistibile. Strain FI-13295 ${ }^{\mathrm{T}}$ grouped with other thermotolerant species, but the unique sequence supports its distinct position within the genus tree. Parsimony analysis confirmed the branches; bootstrapping was performed, but turned out to be of little interest, as is usually the case with sequences that are $>98 \%$ identical.

\section{Differentiation of the novel strain from other related mycobacteria}

Strain FI-13295 ${ }^{\mathrm{T}}$ is a slowly growing, scotochromogenic mycobacterium that can be distinguished from its relatives by a number of properties (Table 2 ). Furthermore, the HPLC profile of strain FI-13295 differs from those of previously mentioned species. The 16S rDNA sequence differentiated strain FI$13295^{\mathrm{T}}$ from other previously described species. 
0.008

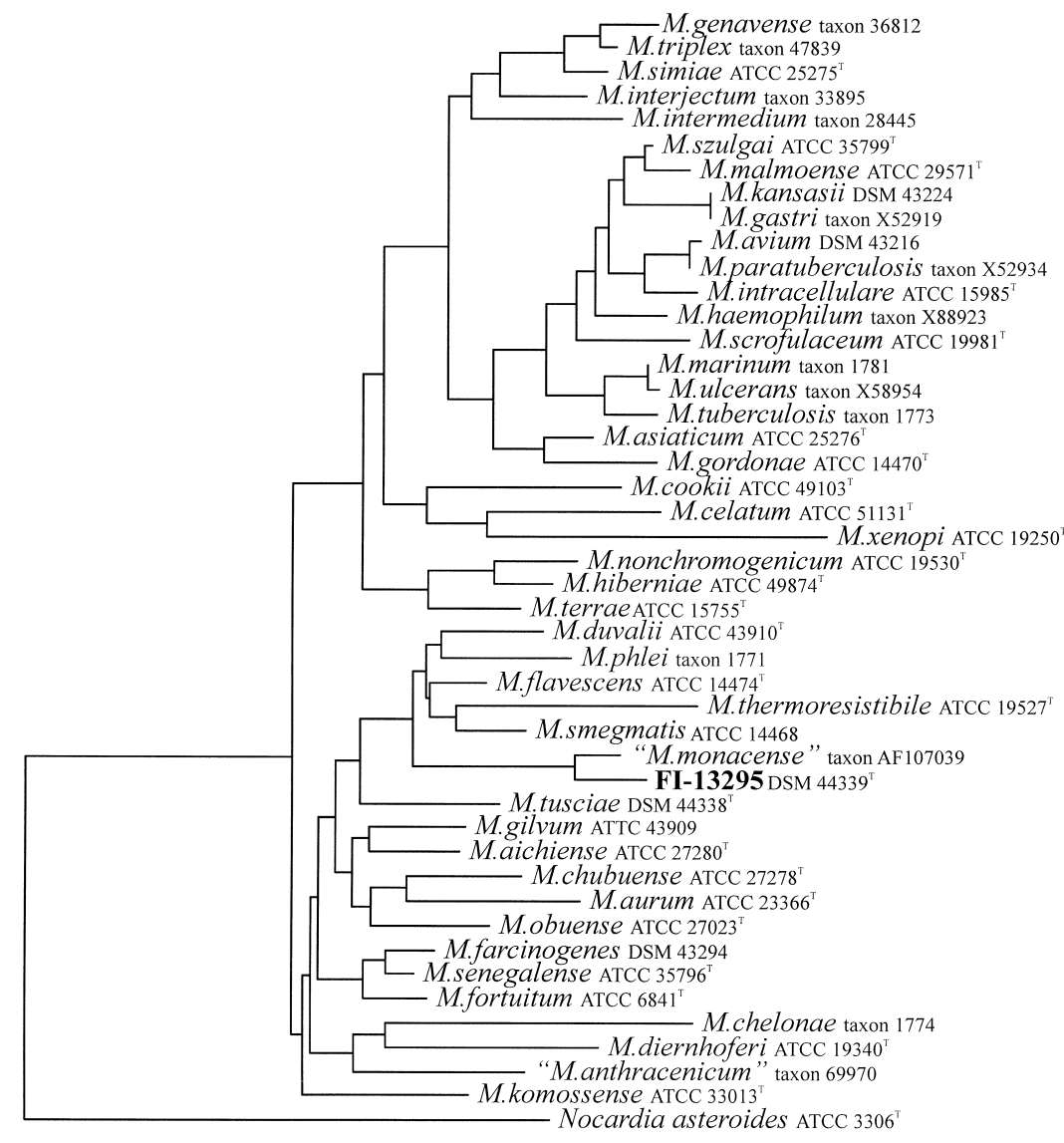

Fig. 2. Phylogenetic tree derived from $16 \mathrm{~S}$ rDNA sequences, rooted with Nocardia asteroides as an outgroup. M., Mycobacterium.

Table 2. Selected characteristics that distinguish strain $\mathrm{Fl}-13295^{\top}$ from other scotochromogenic slowly growing mycobacterial species

Taxa are identified as: 1, strain FI-13295 $; 2$, M. gordonae; 3, M. xenopi; 4, M. scrofulaceum; 5, M. szulgai; 6, M. lentiflavum; 7, M. flavescens; 8, M. interjectum; 9, M. bohemicum. Reactions are scored as: - , negative; +, positive; v, variable. Data were taken from this study and from Wayne \& Kubica (1986), Springer et al. (1993, 1996) and Reischl et al. (1998).

\begin{tabular}{|c|c|c|c|c|c|c|c|c|c|}
\hline Characteristic & 1 & 2 & 3 & 4 & 5 & 6 & 7 & 8 & 9 \\
\hline Nitrate reduction & + & - & - & - & + & - & + & - & - \\
\hline Catalase over $45 \mathrm{~mm}$ & - & + & - & + & + & $\mathrm{V}$ & + & $\mathrm{V}$ & - \\
\hline Tween 80 hydrolysis & - & + & - & - & $\mathrm{V}$ & - & + & $\mathrm{V}$ & - \\
\hline Tellurite reduction & + & - & $\mathrm{V}$ & $\mathrm{V}$ & $\mathrm{V}$ & $\mathrm{V}$ & $\mathrm{V}$ & + & - \\
\hline Arylsulfatase (3 d) & - & - & $\mathrm{V}$ & - & - & - & + & - & - \\
\hline Urease & + & - & - & + & + & $\mathrm{V}$ & - & $\mathrm{V}$ & + \\
\hline$\beta$-Glucosidase & - & - & - & - & + & - & - & - & - \\
\hline $\mathrm{NaCl}$ tolerance & - & - & - & - & - & - & + & - & - \\
\hline Growth at $25^{\circ} \mathrm{C}$ & + & + & - & + & + & + & + & + & $\mathrm{V}$ \\
\hline Growth at $45^{\circ} \mathrm{C}$ & - & - & + & - & - & - & - & - & - \\
\hline
\end{tabular}

\section{DISCUSSION}

Despite its isolation from a sterile site, it is not possible at present to consider strain FI- $13295^{\mathrm{T}}$ as a definite pathogen; C. neoformans could be responsible for the neurological symptoms and the possibility of accidental contamination of the specimen by an environmental mycobacterium cannot be excluded. Nevertheless, considering the unsuccessful response to antimycotic treatment, the involvement of strain FI- 


\begin{tabular}{|c|c|c|}
\hline Region A & & \\
\hline 129 & 177 & \\
\hline 5' TGA TCT GCC CTG CAC TTC & CGG ATA GG-ACCA CGG GAT GCA TGT CT- TGT GGT GGA M. tuberculosis (MTU16SRN) & \\
\hline 5' CA. ... A.. ....... & $\ldots \ldots \ldots \ldots$. . . . ... ................. M. avium (MAV16SRN) & \\
\hline $5^{\prime}$ CA. $\ldots . \cdots \cdots \cdots$ & 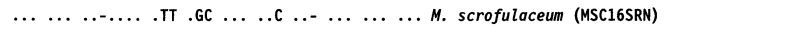 & \\
\hline $5^{\prime} \cdot$.A. $\ldots \ldots \ldots \ldots \ldots$ & $\ldots \ldots \ldots-\ldots . . \mathrm{TT} . \mathrm{GC} \ldots \ldots . . . . \ldots \ldots \ldots \ldots$. simiae (MSI16SRN) & \\
\hline 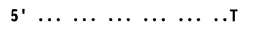 & ... ... ..... . ..C .C. ... ..G TG- ... A.. ... M. farcinogenes (MFAR16S) & \\
\hline $5^{\prime} \ldots \ldots \ldots \ldots \ldots \ldots$ & ... ... т.-... т.. Ас. Т.. С.G Т.- ... ... ... M. komossense (MKOM16S) & \\
\hline 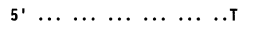 & ... . ... TTCC.TA TT. .TC ... ...G .CT G.. A.G ... M. flavescens (MFL16SRN) & \\
\hline 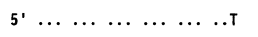 & ..A ... CACC.TG .T. .TC ... ..G .CT G.. A.G ... M. smegmatis (MSM16SRN) & \\
\hline 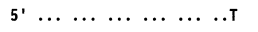 & ... ... тAсCT.. T.. .C. ... ...G T.- ... .AG ... M. tusciae (MTUS16SRN) & \\
\hline $5^{\prime} \ldots \ldots \ldots \ldots \ldots c c c c$ & ..А ... САCC.TG .T. .TC ... ..G .СT G.. ..G ... strain "M. monacense" & \\
\hline $5^{\prime} \ldots \ldots \ldots c c c c c$ & ..A ... СACC.TG .T. .T. ... ...A .CT G.. ..G ... strain FI-13295 & \\
\hline Region B & & \\
\hline 433 & & \\
\hline 5' CCT CTT TCA CCA TCG ACG AA & G G-- TC CGG GTT CTC TCG GAT TGA CGG TAG GTG GAG AAG AAG CAC CGG M. tuberculosis (MTU16SRN) & \\
\hline $5^{\prime} \quad \ldots \ldots \ldots c c c c c$ & 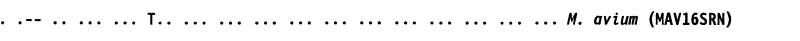 & \\
\hline $5^{1} \quad \ldots \ldots c c c c c c c$ & 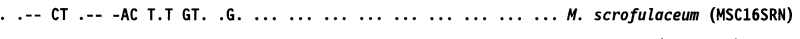 & \\
\hline $5, \ldots \ldots$.... G.. GG. ..... & 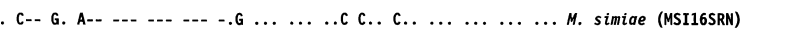 & FIg. 3. Sequences of hypervariable regions A \\
\hline 5' $\ldots$....... At. Gg. ..... & 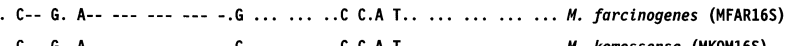 & mycobacterial species. Positions are indicated \\
\hline $5^{\prime} \ldots \ldots$..... GT. GG. $\ldots$.. & 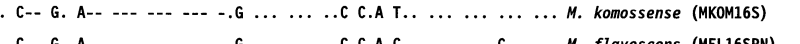 & according to the Escherichia coli sequence. \\
\hline $\begin{array}{l}5 \\
5\end{array}$ & $\begin{array}{l}\text { C.- G. A- } \\
\text { C.- G. A- } \\
\end{array}$ & Only nucleotides that differ from the se- \\
\hline $5^{\prime} \ldots \ldots$... G.. GG. ..... & C.- G. A-- & quence of $M$. tuberculosis are shown; dashes \\
\hline 5' ........ GT. GG. ..... & . C-- G. A-. ... ... -.G ... ....C C.A C.. ..... G.. ... strain "M. monacense" & indicate deletions. GenBank accession num- \\
\hline $5^{\prime} \ldots \ldots$... GT. GG. ..... & 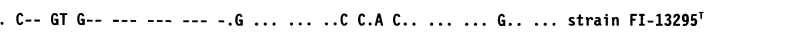 & \\
\hline
\end{tabular}

$13295^{\mathrm{T}}$ in the death of the AIDS patient is still a credible hypothesis.

Conventional tests are sufficient to differentiate this novel organism from other slowly growing, scotochromogenic mycobacteria (Table 2), even if the possibility of bias cannot be excluded because of the lack of additional strains. Its lipid composition is characterized by the presence of $\alpha$-mycolates, ketomycolates and wax esters (Table 1). The mycolic acid bromophenacyl esters generate a unique profile in HPLC (Fig. 1). The fatty acid pattern is composed of hexadecanoic acid $(27 \%)$, hexadecenoic acids (13\%), octadecenoic acids $(26 \%)$ and tuberculostearic acid (16\%). Two alcohols, C18:0 (13\%) and C20:0 (1\%), were found as well.

Sequence analysis of the 16S rRNA gene yielded a sequence that was different from that of any known mycobacterial species. Alignment of the hypervariable regions shows a pattern similar to that of $M$. smegmatis, with differences in both hypervariable regions. The hypervariable region $\mathrm{B}$ shows a deletion of a stretch of 12 nucleotides, usually considered typical of rapidly growing mycobacteria, which is also observed in some slow-growing MOTT (mycobacteria other than tuberculosis), such as Mycobacterium simiae (Fig. 3).

At the phylogenetic level, strain FI-13295 ${ }^{\mathrm{T}}$ is characterized by a distinct position close to other thermotolerant species such as $M$. smegmatis and M. thermoresistibile. Although the sequence was different from that of any other published species at several distinct positions, the novel species is more closely related to another, as-yet unpublished, isolate, 'M. monacense', the sequence of which is accessible from GenBank
(Fig. 3). These findings may suggest the existence of a new cluster of thermotolerant mycobacteria. Interestingly, the phylogenetic position of strain FI$13295^{\mathrm{T}}$ is also close to another recently described mycobacterium, Mycobacterium tusciae (Fig. 3), not known to be thermotolerant (Tortoli et al., 1999).

\section{Description of Mycobacterium doricum sp. nov.}

Mycobacterium doricum (do'ri.cum. L. adj. doricum of Dorica civitas, the ancient name of the Italian city of Ancona, from where the organism was first isolated).

Cells are rod-shaped and alcohol-acid-fast. Growth is achieved on Lowenstein-Jensen medium within about 2 weeks at $25-37^{\circ} \mathrm{C}$. The colonies, which are strongly yellow-pigmented, are scotochromogenic and smooth. Positive for nitrate reductase, tellurite reductase and urease, but negative for niacin, $\beta$-glucosidase, $68{ }^{\circ} \mathrm{C}$ catalase, Tween 80 hydrolysis and 3 -d arylsulfatase. Produces less than $45 \mathrm{~mm}$ of foam in a semiquantitative catalase test. Does not grow on MacConkey agar or on media supplemented with sodium chloride, $p$-nitrobenzoate, thiacetazone, hydroxylamine, isoniazid or oleate. Growth is not inhibited on medium containing thiophene-2carboxylic acid. The strain is susceptible to amikacin, azithromycin, clarithromycin, ciprofloxacin, clofazimine, ethambutol, isoniazid, ofloxacin, rifabutin, rifampicin, sparfloxacin and streptomycin. The lipid composition is characterized by the presence of $\alpha$ mycolates, ketomycolates and wax esters. The HPLC profile of mycolic acid bromophenacyl esters is unique. The fatty acid pattern is composed of hexadecanoic acid $(27 \%)$, hexadecenoic acids $(13 \%)$, octadecenoic acids $(26 \%)$ and tuberculostearic acid $(16 \%)$. Two 
alcohols, $\mathrm{C} 18: 0(13 \%)$ and $\mathrm{C} 20: 0(1 \%)$, are also found. The $\mathrm{G}+\mathrm{C}$ content of the DNA is $66.5 \mathrm{~mol} \%$. The 16S rDNA sequence demonstrates that strain FI- $13295^{\mathrm{T}}$ is phylogenetically related (sharing a similar sequence profile) to the thermotolerant species $M$. thermoresistibile, M. flavescens and M. smegmatis, and to $M$. tusciae which, in contrast, do not present the insertion pattern characteristic of thermotolerant mycobacteria.

The type strain is strain FI-13295 $\left(=\right.$ DSM $44339^{\mathrm{T}}=$ CIP $106867^{\mathrm{T}}$ ).

\section{ACKNOWLEDGEMENTS}

We thank Erik C. Böttger (Institut für Medizinische Mikrobiologie, University of Zurich, Zurich, Switzerland), who first sequenced the hypervariable regions of the strain FI- $13295^{\mathrm{T}} 16 \mathrm{~S}$ rRNA.

\section{REFERENCES}

Böttger, E. C. (1994). Mycobacterium genavense: an emerging pathogen. Eur J Clin Microbiol Infect Dis 13, 932-936.

Butler, W. R., Thibert, L. \& Kilburn, J. O. (1992). Identification of Mycobacterium avium complex strains and some similar species by high-performance liquid chromatography. J Clin Microbiol 30, 2698-2704.

Cage, G. D. \& Saubolle, M. A. (1997). Infrequently isolated and unusual mycobacterial species as agents of human disease. Rev Med Microbiol 8, 125-135.

CDC (1996). Standardized Method for HPLC Identification of Mycobacteria. Atlanta: US Department of Health and Human Services, Public Health Service.

Kent, P. T. \& Kubica, G. P. (1985). Public Health Mycobacteriology. A Guide for the Level III Laboratory. Atlanta: US Department of Health and Human Services.

Kiehn, T. E. \& White, M. (1994). Mycobacterium haemophilum: an emerging pathogen. Eur J Clin Microbiol Infect Dis 13, 925-931.

Kimura, M. (1980). A simple method for estimating evolutionary rates of base substitutions through comparative studies of nucleotide sequences. J Mol Evol 16, 111-120.

Kirschner, P., Springer, B., Vogel, U., Meier, A., Wrede, A., Kiekenbeck, M., Bange, F. C. \& Böttger, E. C. (1993). Genotypic identification of mycobacteria by nucleic acid sequence determination: report of a 2-year experience in a clinical laboratory. J Clin Microbiol 31, 2882-2889.

Larsen, N., Olsen, G. J., Maidak, B. L., McCaughey, M. J., Overbeek, R., Macke, T. J., Marsh, T. L. \& Woese, C. R. (1993). The ribosomal database project. Nucleic Acids Res 21, 3021-3023.

Miller, L. T. (1982). Single derivatization method for routine analysis of bacterial whole-cell fatty acid methyl esters, including hydroxy acids. J Clin Microbiol 16, 584-586.

Minnikin, D. E., Minnikin, S. M., Parlett, J. H., Goodfellow, M. \& Magnusson, M. (1984). Mycolic acid patterns of some species of Mycobacterium. Arch Microbiol 139, 225-231.

Reischl, U., Emler, S., Horak, Z., Kaustova, J., Kroppenstedt, R. M., Lehn, N. \& Naumann, L. (1998). Mycobacterium bohemicum sp. nov., a new slow-growing scotochromogenic mycobacterium. Int J Syst Bacteriol 48, 1349-1355.

Saitou, N. \& Nei, M. (1987). The neighbor-joining method: a new method for reconstructing phylogenetic trees. Mol Biol Evol 4, 406-425.

Sanger, F., Coulson, A. R., Hong, G. F., Hill, D. F. \& Petersen, G. B. (1982). Nucleotide sequence of bacteriophage lambda DNA. J Mol Biol 162, 729-773.

Siddiqi, S. H., Heifets, L. B., Cynamon, M. H., Hooper, N. M., Laszlo, A., Libonati, J. P., Lindholm-Levy, P. J. \& Pearson, N. (1993). Rapid broth macrodilution method for determination of MICs for Mycobacterium avium isolates. J Clin Microbiol 31, 2332-2338.

Springer, B., Kirschner, P., Rost-Meyer, G., Schröder, K. H., Kroppenstedt, R. M. \& Böttger, E. C. (1993). Mycobacterium interjectum, a new species isolated from a patient with chronic lymphadenitis. J Clin Microbiol 31, 3083-3089.

Springer, B., Wu, W. K., Bodmer, T. \& 11 other authors (1996). Isolation and characterization of a unique group of slowly growing mycobacteria: description of Mycobacterium lentiflavum sp. nov. J Clin Microbiol 34, 1100-1107.

Tamaoka, J. \& Komagata, K. (1984). Determination of DNA base composition by reverse-phase high-performance liquid chromatography. FEMS Microbiol Lett 25, 125-128.

Tortoli, E. \& Bartoloni, A. (1996). High-performance liquid chromatography and identification of mycobacteria. Rev Med Microbiol 7, 207-219.

Tortoli, E., Kroppenstedt, R. M., Bartoloni, A., Caroli, G., Jan, I., Pawlowski, J. \& Emler, S. (1999). Mycobacterium tusciae sp. nov. Int J Syst Bacteriol 49, 1839-1844.

Wayne, L. G. \& Kubica, G. P. (1986). Family Mycobacteriaceae Chester 1897, 63 ${ }^{\mathrm{AL}}$. In Bergey's Manual of Systematic Bacteriology, vol. 2, pp. 1436-1457. Edited by P. H. A. Sneath, N. S. Mair, M. E. Sharpe \& J. G. Holt. Baltimore: Williams \& Wilkins. 